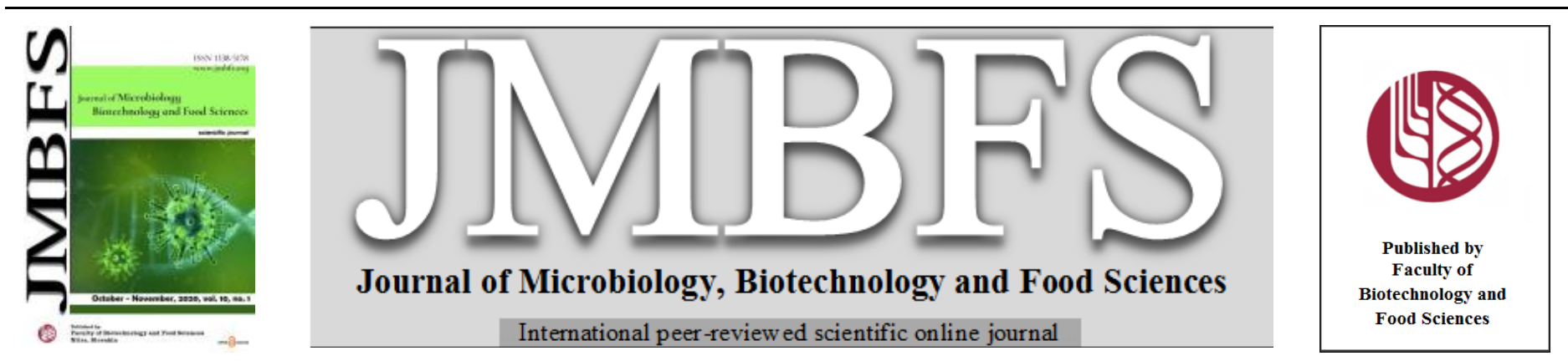

\title{
PURIFICATION, CHARACTERIZATION AND EXPRESSION, OF RECOMBINANT OUTER MEMBRANE PROTEIN A (OMP A) OF ACINETOBACTER BAUMANNII LI311
}

\author{
Aamal Ghazi Mahdi Al-Saadi ${ }^{\text {**, Aalaa Fahim Abbas }}{ }^{2}$ \\ Address(es):
${ }_{1,2}$ University of Al-Qadisiyah, College of Science, Department of Ecology, Al Diwaniyah58001, Iraq.
}

*Corresponding author: amal.alssdi@qu.edu.iq

doi: 10.15414/jmbfs.2020.10.2.317-320

\section{ARTICLE INFO}

Received 16.3. 2020

Revised 29. 6. 2020

Accepted 30. 6. 2020

Published 1. 10. 2020

Regular article

OPEN $\partial_{\text {ACCESS }}$

\begin{abstract}
Acinetobacter baumannii is a known hospital aquired pathogenic bacterium that increasingly resists antibiotics treatment. In order to characterize and produce a soluble OmpA protein that can be used to develop Acinetobacter vaccine, polymerase chain reaction (PCR) was used to produce the ompA gene, of A. baumannii strain LI311, which was cloned into the histidin taged pET19b expression plasmid. Immobilized metal affinity chromatography (IMAC) was utilized to purify the recombinant protein, and amino acid sequences for OmpA protein homologs were attained from the National Center for Biotechnology Information (NCBI) protein resource then analyzed using the blast tool and Jalview program. Protein topology prediction was done using NCBI tools and PRED-TMBB2. Analysis of amino acid sequence of OmpA of A. baumannii strain LI311 showed that it has homologies to other clinical Acinetobacter spices, including: A. pittii, A.nosocomialis , A.seifertii, A. calcoaceticus, and A. ursingii with identity percentages of $100 \%, 100 \%, 96 \%, 92 \%$, and $91 \%$. Protein topology prediction revealed two conserved domains belonging to OmpA family protein ,which are beta-barrel domain outer membrane protein (OMP_b-brl) and OmpA-C-like domain, and it is a 10-ßeta -stranded transmembrane Outer Membrane Protein with a signal peptide at residues 1-22A. A recombinant Histidine tagged- OmpA (39.31kDa )was successfully expressed and purified in this study. In conclusion, OmpA protein of A.baumannii strain LI31 is highly conserved across clinical species of Acinetobacter, and the soluble recombinant OmpA created in this study can be used to develop a putative vaccine that may prevent infections caused by the clinical species of Acinetobacter.
\end{abstract}

Keywords: Acinetobacter baumannii, ompA gene, expression, homology, putative vaccine

\section{INTRODUCTION}

The Gram-negative genus, Acinetobacter, involves a naturally varied group of aerobic bacteria, non-fastidious, oxidase negative , unable to motile ,catalasepositive bacilli (Peleg et al., 2008). Although Acinetobacter members are generally depicted as ubiquitous nonpathogenic bacteria, strains of the Acinetobacter baumannii-Acinetobacter calcoaceticus become apparent as important opportunistic pathogenic bacteria to humans(Dijkshoorn et al., 2007; Perez et al., 2007). The capability of $A$. baumannii to have numerous virulence factors, such as iron gaining mechanisms, motility, and efflux force in unfavorable environmental circumstances helps this bacterium to develop infections. A. baumannii has the ability to survive and resist in hospitals conditions, so it has become one of the highly thriving hospital acquired pathogenic bacterium that can stimulate cruicial infections to humans((Howard et al., 2012; Montefour et al., 2008; Peleg et al., 2008). Moreover, this bacterium is implicated in outbreaks happening in rigorous hospital rooms((Bergogne-Berezin and Towner, 1996), and it is frequently a source of pneumonia, blood poisoning, and cystisis after hospitalization of people with further strict diseases (Coelho et al., 2004). The potential pathogenicity of A. baumannii includes the surfaces adherence capability, biofilms formation, antimicrobial resistance, and acquisition of genetic materials from distinct genera(Anstey et al., 2002; Howard et al., 2012). As resistance to multiple antibiotics among A. baumannii are increasing (Kuo et al., 2007; Qureshi et al., 2015 ), prevention and cure of diseases caused by this pathogen have become a major health care threat; therefore, novel approaches to manage and prevent A. baumannii infections are required. Although vaccination signifies the greatest strategy to prevent A. baumannii infections ((Mishra et al. 2012; Pachon \& McConnell, 2014 ), no effective vaccine has been developed for this pathogen to date. Antigens that induce immunity against proteins of the bacterial outer membrane are vital antigen candidates because of their ability to interact with the host as well as their position on the cell surface, which make them available for antibody neutralization (McConnell et al., 2011). The potential and viability of immunization have previously been validated through active and passive immunization to the outer membrane protein $\mathrm{A}(\mathrm{OmpA})$ (Fattahian et al., 2011 ) (Luo et al., 2012) and a multifunctional trimeric autotransporter (Ata) antigens (Bentancor et al., 2012a ). Nevertheless, the prevalence and solubility of these antigens represent major obstructions for achievement of a generally protecting vaccine.

The outer membrane proteins (OMPs) in Gram negative bacteria are distinctive classes of essential membrane proteins. These proteins have vital functions for the cell, such as adhesion, nutrients utilization, signaling, secretion of waste as well as serving as a virulence factor in pathogenic strains. OMPs are highly stabile in membrane and capable of resisting very severe environments because their $\beta$-barrel domains have 8 to 26 strands. The large, expanded loops linking the strands on the extracellular region, while the small loops were found on the periplasmic area (Rollauer et al., 2015). The OMPs possess comparable composition and biological features even though they have diverse sequences (Chaturvedi and Mahalakshmi, 2017). The variety of OMPs sequence is much more at $\mathrm{N}$ terminal significantly than $\mathrm{C}$ terminal, and proper assembly and folding of OMPs is controlled by the conserved $\beta$ strands (Gessmann $\boldsymbol{e t}$ al., 2014). Nevertheless, the kinds of OMPs in A. baumannii have not been characterized evidently, up to now, and only some reports are exist, including Omp33-36, OmpW, and OmpA (Choi \& Lee, 2019). Amomg them, OmpA is extremely abundant protein on A. baumannii surface, and it is implicated in bacterial growth, virulence, and drugs resistance. Due to the high immunogenic properties of OmpA, it has been previously identified as a putative antigen to develope vaccines as well as passive immunotherapy for diseases caused by this bacterium (Fajardo Bonin et al., 2014; Moriel et al., 2013). Interestingly, OmpA of strain LI31 of A. baumannii is found to be a homolog to OmpA of other clinical Acinetobacter spices, including, Acinetobacter pittii, Acinetobacter nosocomialis, Acinetobacter seifertii, Acinetobacter ursingii ,the possible causes of bacterimia (Kishii et al., 2016; Liu et al., 2017; Loubinoux et al., 2003 ), Acinetobacter calcoaceticus that causes burns and wounds infections (Pavlica and Tomanovic, 1989 ). A successful vaccine antigen to A. baumanni infections may be helpful to protect against Acinetobacter spices; therefore , the current study aimed to: 
1. Create a soluble recombinant OmpA protein that can be used as antigen candidate in Acinetobacter vaccine through cloning the corresponding ompA open reading frame from A.baumannii strain LI31 into pET19b vector, expressing the histidine tagged OmpA protein, and purifying the fused OmpA using immobilized metal affinity chromatography (IMAC).

2. Analyze the sequence of OmpA amino acid sequence of A.baumannii strain LI31 for toplogy prediction and conservation .

\section{MATERIAL AND METHODS}

\section{Amplification of ompA gene}

DNA of Acinetobacter baumannii strain LI311( standard strain obtained from the central health lab in Baghdad )was elicited using bacterial RTP® extraction Kit (InVitek- Germany). Primers used for detection of $о m p A$ gene were designed using clone manager software based on the published sequence of the gene on NCBI (Accession number: EU332799). The sequence of the forward primer including XhoI restriction site was:- 5' CTCGAGGGAATGAAATTGAG3'. The sequence of the reverse primer with $B \operatorname{lpI}$ restriction site was: - 5' GTGTATTCGCGACAGCTGAGC3'. The entire ompA code (1002 bps) was synthesized utilizing the PCR Kit, Phusion TM High-Fidelity from Thermo Fisher scientific. PCR testing was executed in a final amount of $50 \mu \mathrm{L}$ of test combination which contains $0.5 \mu \mathrm{M}$ for each primer, $25 \mu \mathrm{L}$ of $2 \mathrm{X}$ Phusion Master Mix, $100 \mathrm{ng} / 50 \mu \mathrm{L}$ of DNA, and nuclease liberated water. DNA was synthesized to be first denatured for 30 seconds on $98^{\circ} \mathrm{C}$ then for 10 seconds $(30$ rounds), annealed at $54^{\circ} \mathrm{C}$ intended for half a minute, elongated by $72^{\circ} \mathrm{C}$ for a period of 40 seconds, and last extended on $72^{\circ} \mathrm{C}$ for a period of 5 minutes. The product was visualized by agarose gel system using $1 \%$ gels supplemented with ethidium bromide $(0.5 \mu \mathrm{g} / \mathrm{ml})$. Gels were explicated via a ChemiDoc MP (BioRad). Bands matching the predictable size of ompA gene with restriction sites (1018 bp) then extracted from the gel by the Thermo scientific Gene Extraction Kit.

\section{Creation and validation of recombinant construct}

The histidne tagged pET19b and PCR fragment were cut by Fast Diges restriction enzymes (XhoI and $B l p I$ ) (Thermo scientific). The cut PCR fragment were then cloned into the digested vector using T4 DNA ligase and ligase buffer. The ligated recombinant vectors were then moved into $E$. coli strain DH5a(Thermo Fisher Scientific) then cultivated on Luria-Bertani (LB) plates having hundred microgram per mililiter of ampicillin for selection. Clones were chosen randomly and cultivated on $37{ }^{\circ} \mathrm{C}$ in a test tube having five mliliters of LB broth and ampicillin $(100 \mu \mathrm{g} / \mathrm{ml})$. Constructs were extracted from overnight cultures employing the Gene JETTM Plasmid Mini prep Kit (Thermo scientific). Recombinant vectors were validated by colony PCR, cutting by restriction enzymes, and DNA base Sequencing using a DNA automatic sequencer. For protein production, the created construct was moved to E. coli BL21 (DE3)(NEWENGLAND Biolabs). The creation and validation of our construct was done following the istructions of pET System Manual2 (Novagen).

Omp A protein induction and expression
One colony of the expresion E. coli strain having pET19b-ompA, was inoculated in a tube having three milliliters of LB broth suplimented with ampicillin then put in a shaker incubator at $37{ }^{\circ} \mathrm{C}$ overnight. Samples then were sub-cultured at 1:100 in six milliliters of $\mathrm{LB} /$ ampicillin broth then put in an incubater adjusted to $37{ }^{\circ} \mathrm{C}$. A spectrophotometer was used to measure the (OD) at $600 \mathrm{~nm}$, and when it was about $0.6-0.8$ and before protein production, $500 \mu \mathrm{L}$ of each sample was taken; then isopropyl-D-thiogalactopyranoside( IPTG ) was mixed at $1 \mathrm{mM}$ with the growing cultures. The induced bacterial cells were cultivated in a shaker incubator at $37^{\circ} \mathrm{C}$ for a period of 3 hours; a post induction sample $(500 \mu \mathrm{L})$ was possessed then centrifuged at $13 \mathrm{rpm}, 4{ }^{\circ} \mathrm{C}$ for two minutes. Supernatants were removed and $125 \mu \mathrm{L}$ of $1 \mathrm{X}$ laemmli buffer was mixed with the pellet. Pellets were vortexed and placed in a $90{ }^{\circ} \mathrm{C}$ hot block for five minutes prior to storage at $-20{ }^{\circ} \mathrm{C}$. Protein samples were examined utilizing SDS-PAGE and western blotting(10\% gels) using Mouse monoclonal IgG anti-His (Millipore) (NEB) primary antibodies and the Goat anti-mouse IgG secondary antibody (Millipore). The blots images were captured using a Bio-Rad (ChemiDoc MP).Protein induction and expression was done following the istructions of pET System Manual2 (Novagen)

\section{Purification of the histidine-tagged OmpA}

Immobilized metal affinity chromatography (IMAC) (Nickel-chelated) was utilized in order to purify the histidine-tagged OmpA from the expression $E$ coli strain as described in(Chiang et al., 2015). The fusion histidine-tagged OmpA, was validated using SDS-PAGE as well as western blot.

\section{Sequencing alignments}

Amino acid sequences for OmpA protein homologs were attained from (NCBI) protein resource then analyzed using the blast tool (NCBI). Homologs for Omp A protein from other pathogenic Acinetobacter spp were chosen [Accession numbers: ABY47586.1, WP_044100281.1,WP_107972446.1, WP 111034814.1,PMC94806.1, WP_016137162.1] and aligned using clustal Omega website. The color shades were given according to \% identity coloring of Jalview.

\section{Topology prediction}

Protein topology prediction was done using NCBI tools and PREDTMBB2(Elofsson et al., 2016)

\section{RESULTS}

\section{Topology prediction of OmpA from A.baumannii strain LI31}

Sequence analysis of OmpA from A.baumannii strain LI31 revealed two conserved domains belonging to OmpA family protein: OMP_b-brl and OmpA_C-like ( Figure 1.A). These domains are highly conserved acrooss Acinetobacter spp. Results from topology prediction revealed the OmpA peptide as a 10 - $\beta$ eta -stranded transmembrane outer membrane protein categorized as the Outer Membrane Protein beta-barrel domain Family(Figure1.B)

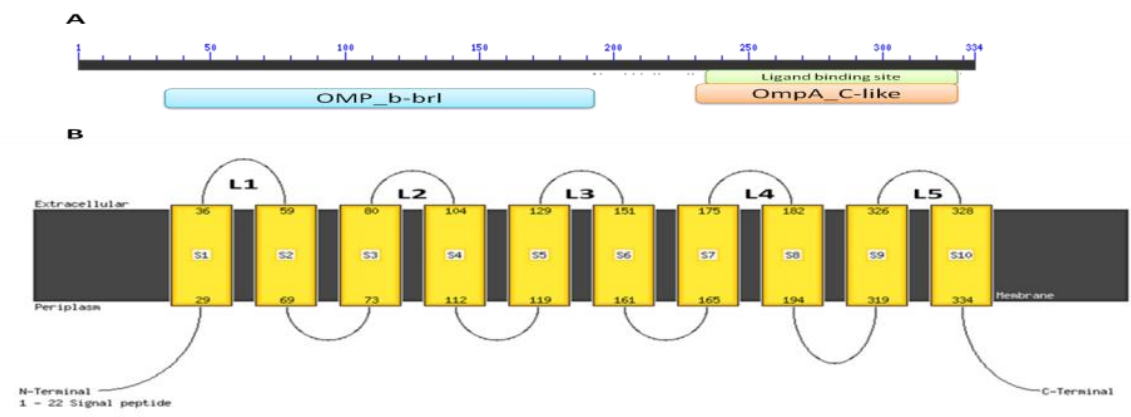

Figure 1 Topology prediction of OmpA of A.baumannii strain LI31.A. Conserved domains were identified based on the BLAST search tool of NCBI. B. External loops: L1-L5, transmembrane $\beta$ strands: B1-B10 based on PRED-TMBB2

\section{Analysis of OmpA conservation within Acinetobacter spp}

Representative alignments for Sequence of the Omp A of A. baumannii strain LI311 with homologous sequences of OmpA protein from other
Acinetobacterspp is shown in Figure2. Selected homologous sequnces belong to Acinetobacter pittii, Acinetobacter seifertii, Acinetobacter nosocomialis , Acinetobacter calcoaceticus , Acinetobacter ursingii with identity percentages of $100 \%, 100 \%, 96 \%, 92 \%, 91 \%$ respectively 

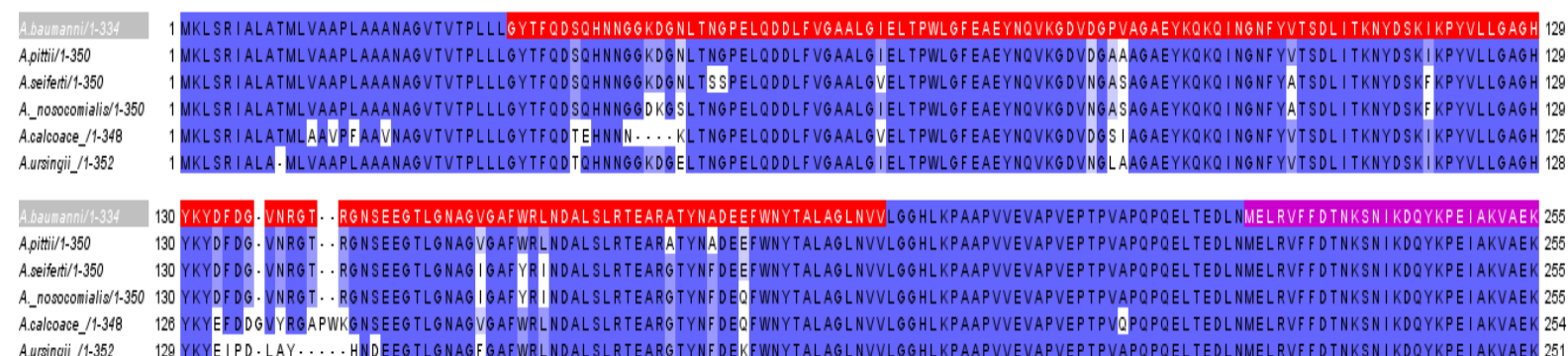

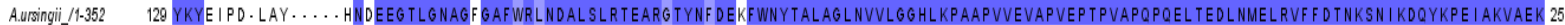

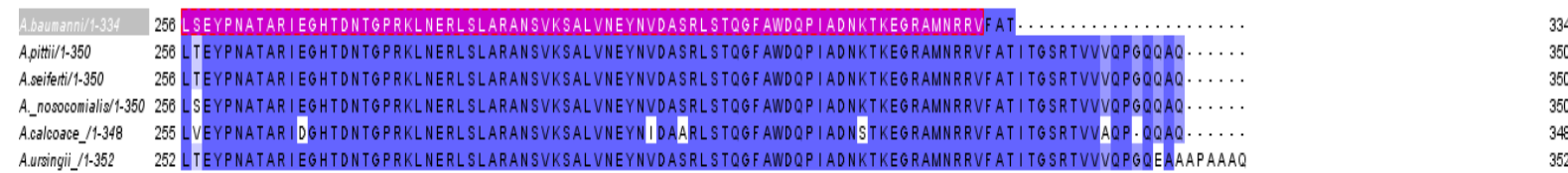

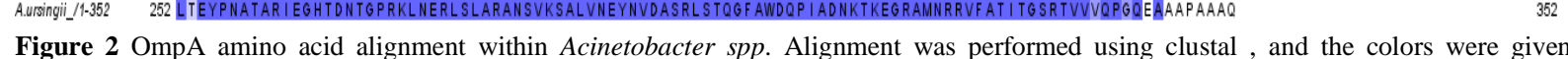
according to \% identity coloring of Jalview. OMP_b-brl is denoted by red and OmpA_C-like is denoted by purple

\section{Creation and validation of recombinant construct}

The amplified ompA gene from Acinetobacter baumannii strain LI311 (1018 bp) was cut by XhoI and BlpI and ligated into the matching positions of pET19b plasmid digested with the same restriction enzymes. Clones were selected randomly from LB/ Ampicillin plates for PCR verification (Figure 3.A).The recombinant plasmid, pET19b-ompA, was also validated by restriction digestion using XhoI and BlpI and analyzed by agarose gel electrophoresis (Figure 3.B) Sequencing of DNA was utilized using a DNA automatic sequencer in order to ensure there is no mutation. The nucleotide sequence of $о m p A$ gene in the created construct of pET19b-ompA was consistent with ompA gen sequenc of Acinetobacter baumannii strain LI311 published in the GenBank (Accession: EU332799).

A

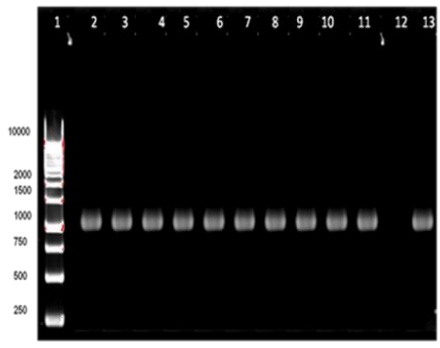

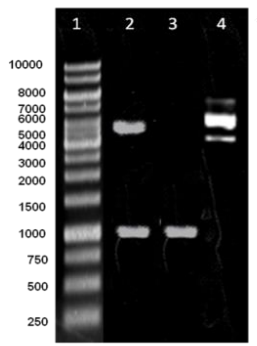

Figure 3 Agarose gel electrophoresis analysis and confirmation of the fused pET19b-ompA by A. colony PCR.Lane1: 10000bp DNA marker, Lanes 2-11: the target amplification of ompA gene (Predicted size is 1018bp), lane 12: negative control, and lane 13: positive control. B. Restriction digestion. Lane1: 10000 bp DNA marker, Lane 2: pET19b-ompA digested with XhoI and BlpI, Lane 3: ompA gene, Lane 4: uncut pET19b-ompA. Expected size of pET19b : 5671 bp, pET19b-ompA : 6673bp, ompA gene :1018bp

\section{Expression and purification of Hist-tagged OmpA fusion protein}

The Hist-tagged OmpA was successfully expressed using $1 \mathrm{mM}$ of IPTG, and purification is done by Nickel-chelated immobilized metal affinity chromatography (Figure 4).

A

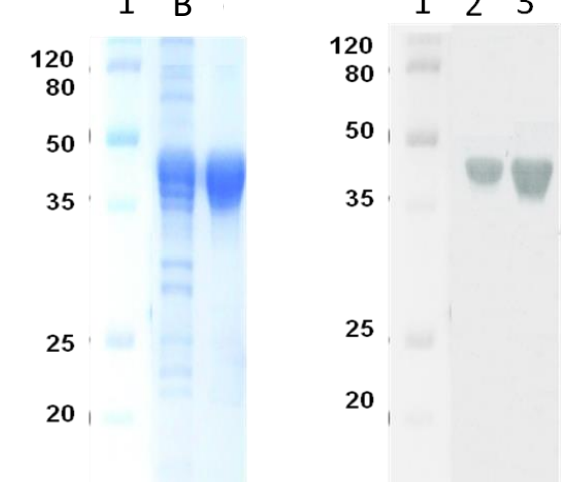

Figure 4 Sodium Dodisyle Sulfate -PAGE (A) and Western bloting (B) of purified His-OmpA. Lane1: molecular protein marker, Lane2: cell lysate after induction of His- OmpA by $1 \mathrm{mM}$ IPTG, Lane3: purified His-OmpA. The expected molecular weight of His- OmpA is $39.31 \mathrm{kDa}$ )

\section{DISCUSSION}

Acinetobacter baumannii is a significant microorganism that can affect humans health nowadays due to the brisk appearance and dissemination of strains capable of resistting antimicrobial agents with elivated mortality rates related to their infections((Wang-Lin et al., 2017). Despite that there is no authorized vaccine at present to A.baumannii, immunization approaches are promising as a feasible choice to control multi- resistant infections. One of the most important principles that should be taken for consideration when selecting an antigen from the proteome of a specified pathogen is that it has to be ubiquitous and conserved among diverse bacterium strains((Ahmad et al., 2016; Chen, 2015 ). OmpA of A.baumannii strain LI31, encodes the polypeptides of 334 amino acids, was selected as a putative vaccine in this study because the blast analysis of OmpA of this bacterium showed that this protein is not only completely conserved across various strains of A.baumannii, but it is also a homolog to OmpA of some clinical Acinetobacter species, among them, A. pittii, A. nosocomialis, A. seifertii, A. calcoaceticus, and A. ursingii with identity percentages of $100 \%, 100 \%, 96 \%, 92 \%, 91 \%$ respectively. In addition, the OmpA protein of A.baumannii possesses high immunogenic property making it as a putative antigen for vaccines development(Fajardo Bonin et al., 2014). Sequence analysis of OmpA from A.baumannii strain LI31 revealed two conserved domains belonging to OmpA family protein (domain architecture ID 10607194). The first is OMP_b-brl, which is identified in a broad range of outer membrane proteins as a membrane bound beta. The second domain is OmpA_Clike, which is peptidoglycan binding domain like the carboxyl terminal domain of OmpA ( Marchler-Bauer et al., 2017). These domains are highly conserved acrooss Acinetobacter spp. The topology prediction revealed the OmpA peptide as a 10-ßeta -stranded transmembrane outer membrane protein categorized as the Outer Membrane Protein beta-barrel domain Family). Residues 1-22 were considerd as a signal peptide.

A. baumannii is the favored genus of Acinetobacter for scientists to produce vaccine because it is linked to the greatest rate of morbidness, lethality, and antibiotics resistance (ournier \& Richet, 2006 ). To present, confined research were done on A. baumannii to find effective immunization approaches. Among which, active and passive immunization against the biofilm assiociated protein (Bap) ((Fattahian et al., 2011), OmpA(Luo et al., 2012 ), poly-N-acetyl- $\beta-(1-$ 6)-glucosamine (PNAG)( Bentancor et al., 2012b ), Ata(Bentancor et al., 2012 ) , and polysacharade capsule (Russo et al., 2010) were tested. In addition,62 antigens were determined in the entire species of $A$. baumannii, which could be utilized as vaccin candidates; among them ompA was considers as one of these possible targets

(Moriel et al., 2013).Furthermore, a previous study showed that active and passive immunization can be produced by recombinant OmpA protein after infecting diabetic mice by $A$. baumannii eventhough sera resistance was not accomplished (Luo et al., 2012) . OmpA protein is also demonstrated to be able prevent infections of A. baumannii in mice by trigaring signal pathways of INF- $\gamma$ and IL-4(Lin et al., 2013 ). In addition,in a recently published study, eukaryotic expression vector,pBudCe4.1, was used to clone and express ompA gene of $A$. baumannii as a DNA vaccine, but the researchers reffered to the oncogenic posibility of the created recombinant molecules after an irregular combination with hosts genomes (Ansari et al., 2018).

\section{CONCLUSION}

In this report, a soluble recombinant OmpA protein of A.baumannii strain LI31, immensely conserved across clinical species of Acinetobacter, was successfully produced and purified. The outcome of our research can be employed to develop a vaccine candidate for Acinetobacter infections. 
Acknowledgments: Thanks for University of Al -Qadisiyah, Iraq to support us for performing our research.

\section{REFERENCES}

Ahmad, T. A., Tawfik, D. M., Sheweita, S. A., Haroun, M., \& El-Sayed, L. H (2016). Development of immunization trials against Acinetobacter baumannii. Trials in Vaccinology, 5, 53-60. doi:https://doi.org/10.1016/j.trivac.2016.03.001 Ansari, H., Doosti, A., Kargar, M., Bijanzadeh, M., \& Jaafarinia, M. (2018). Cloning of ompA gene from Acinetobacter baumannii into the eukaryotic expression vector pBudCE4.1 as DNA vaccine. Indian J Microbiol, 58(2), 174 181. https://doi.org/10.1007/s12088-017-0705-X

Anstey, N. M., Currie, B. J., Hassell, M., Palmer, D., Dwyer, B., \& Seifert, H (2002). Community-acquired bacteremic Acinetobacter pneumonia in tropical Australia is caused by diverse strains of Acinetobacter baumannii, with carriage in the throat in at-risk groups. $J$ Clin Microbiol, 40(2), 685-686. https://doi.org/10.1128/jcm.40.2.685-686.2002

Bentancor, L. V., Camacho-Peiro, A., Bozkurt-Guzel, C., Pier, G. B., \& MairaLitrán, T. (2012)a. Identification of Ata, a multifunctional trimeric autotransporter of Acinetobacter baumannii. $J$ Bacteriol. https://doi.org/10.1128/JB.06769-11

Bentancor, L. V., O'Malley, J. M., Bozkurt-Guzel, C., Pier, G. B., \& MairaLitran, T. (2012)b. Poly-N-acetyl-beta-(1-6)-glucosamine is a target for protective immunity against Acinetobacter baumannii infections. Infect Immun, 80(2), 651-656. https://doi.org/10.1128/IAI.05653-11

Bergogne-Berezin, E., \& Towner, K. J. (1996). Acinetobacter spp. as nosocomial pathogens: microbiological, clinical, and epidemiological features. Clin Microbiol Rev, 9(2), 148-165.

Chaturvedi, D., \& Mahalakshmi, R. (2017). Transmembrane $\beta$-barrels: Evolution, folding and energetics. Biochim Biophys Acta Biomembr, 1859(12), 2467-2482. https://doi.org/10.1016/j.bbamem.2017.09.020

Chen, W. (2015). Current advances and challenges in the development of Acinetobacter vaccines. Hum Vaccin Immunother, 11(10), 2495-2500. https://doi.org/10.1080/21645515.2015.1052354

Chiang, M. H., Sung, W. C., Lien, S. P., Chen, Y. Z., Lo, A. F., Huang, J. H. Kuo, S. C. Chong, P. (2015). Identification of novel vaccine candidates against Acinetobacter baumannii using reverse vaccinology. Hum Vaccin Immunother, 11(4), 1065-1073. https://doi.org/10.1080/21645515.2015.1010910

Choi, U., \& Lee, C. R. (2019). Antimicrobial Agents That Inhibit the Outer Membrane Assembly Machines of Gram-Negative Bacteria. J Microbio Biotechnol, 29(1), 1-10. https://doi.org/10.4014/jmb.1804.03051

Coelho, J., Woodford, N., Turton, J., \& Livermore, D. M. (2004). Multiresistant acinetobacter in the UK: how big a threat? J Hosp Infect, 58(3), 167-169. https://doi.org/10.1016/j.jhin.2003.12.019

Dijkshoorn, L., Nemec, A., \& Seifert, H. (2007). An increasing threat in hospitals: multidrug-resistant Acinetobacter baumannii. Nat Rev Microbiol, 5(12), 939-951. https://doi.org/10.1038/nrmicro1789

Elofsson, A., Tsirigos, K. D., \& Bagos, P. G. (2016). PRED-TMBB2: improved topology prediction and detection of beta-barrel outer membrane proteins Bioinformatics, 32(17), i665-i671. https://doi.org/10.1093/bioinformatics/btw444 Fajardo Bonin, R., Chapeaurouge, A., Perales, J., Silva, J. G., do Nascimento, H. J., D'Alincourt Carvalho Assef, A. P., \& Moreno Senna, J. P. (2014). Identification of immunogenic proteins of the bacterium Acinetobacter baumannii using a proteomic approach. PROTEOMICS - Clinical Applications 8(11-12), 916-923. https://doi.org/10.1002/prca.201300133

Fattahian, Y., Rasooli, I., Mousavi Gargari, S. L., Rahbar, M. R., Darvish Alipour Astaneh, S., \& Amani, J. (2011). Protection against Acinetobacter baumannii infection via its functional deprivation of biofilm associated protein (Bap). Microb Pathog, 51(6), 402- 406 doi:https://doi.org/10.1016/j.micpath.2011.09.004

Fournier, P. E., \& Richet, H. (2006). The epidemiology and control of Acinetobacter baumannii in health care facilities. Clin Infect Dis, 42(5), 692-699. https://doi.org/10.1086/500202

Gessmann, D., Chung, Y. H., Danoff, E. J., Plummer, A. M., Sandlin, C. W., Zaccai, N. R., \& Fleming, K. G. (2014). Outer membrane $\beta$-barrel protein folding is physically controlled by periplasmic lipid head groups and BamA. Proc Natl Acad Sci U S A, 111(16), 5878-5883. https://doi.org/10.1073/pnas.1322473111

Howard, A., O’Donoghue, M., Feeney, A., \& Sleator, R. D. (2012). Acinetobacter baumannii: An emerging opportunistic pathogen. Virulence, 3(3), 243-250. https://doi.org/10.4161/viru.19700

Kishii, K., Kikuchi, K., Tomida, J., Kawamura, Y., Yoshida, A., Okuzumi, K., \& Moriya, K. (2016). The first cases of human bacteremia caused by Acinetobacter seifertii in Japan. Journal of Infection and Chemotherapy, 22(5), 342-345. doi:https://doi.org/10.1016/j.jiac.2015.12.002

Kuo, L. C., Lai, C. C., Liao, C. H., Hsu, C. K., Chang, Y. L., Chang, C. Y., \& Hsueh, P. R. (2007). Multidrug-resistant Acinetobacter baumannii bacteraemia: clinical features, antimicrobial therapy and outcome. Clin Microbiol Infect, 13(2), 196-198. https://doi.org/10.1111/j.1469-0691.2006.01601.x

Lin, L., Tan, B., Pantapalangkoor, P., Ho, T., Hujer, A. M., Taracila, M. A., Bonomo, R. A. Spellberg, B. (2013). Acinetobacter baumannii rOmpA vaccine dose alters immune polarization and immunodominant epitopes. Vaccine, 31(2), 313-318. https://doi.org/10.1016/j.vaccine.2012.11.008

Liu, Y.-M., Lee, Y.-T., Kuo, S.-C., Chen, T.-L., Liu, C.-P., \& Liu, C.-E. (2017) Comparison between bacteremia caused by Acinetobacter pittii and Acinetobacter nosocomialis. Journal of Microbiology, Immunology and Infection, 50(1), 62-67. https://doi.org/10.1016/j.jmii.2015.01.003

Loubinoux, J., Mihaila-Amrouche, L., Le Fleche, A., Pigne, E., Huchon, G. Grimont, P. A. D., \& Bouvet, A. (2003). Bacteremia Caused by Acinetobacter ursingii. Journal of clinical microbiology, 41(3), 1337-1338. https://doi.org/10.1128/jcm.41.3.1337-1338.2003

Luo, G., Lin, L., Ibrahim, A. S., Baquir, B., Pantapalangkoor, P., Bonomo, R. A., Doi, Yohei., Adams, Mark D., Russo, Thomas A. Spellberg, B. (2012). Active and Passive Immunization Protects against Lethal, Extreme Drug ResistantAcinetobacter baumannii Infection. PLoS One, 7(1), e29446. https://doi.org/10.1371/journal.pone.0029446

Marchler-Bauer, A., Bo, Y., Han, L., He, J., Lanczycki, C. J., Lu, S., Marchler, G. H., Song, J. S.,Thanki, N.,Wang, Z.,Yamashita, R. A.,Zhang, D.,Zheng, C.,Geer, L. Y. Bryant, S. H. (2017). CDD/SPARCLE: functional classification of proteins via subfamilydomain architectures. Nucleic Acids Res, 45(D1), D200d203. https://doi.org/10.1093/nar/gkw1129

McConnell, M. J., Dominguez-Herrera, J., Smani, Y., Lopez-Rojas, R., DocoboPerez, F., \& Pachon, J. (2011). Vaccination with outer membrane complexes elicits rapid protective immunity to multidrug-resistant Acinetobacter baumannii. Infect Immun, 79(1), 518-526. https://doi.org/10.1128/IAI.00741-10

Mishra, R. P., Oviedo-Orta, E., Prachi, P., Rappuoli, R., \& Bagnoli, F. (2012) Vaccines and antibiotic resistance. Curr Opin Microbiol, 15(5), 596-602 https://doi.org/10.1016/j.mib.2012.08.002

Montefour, K., Frieden, J., Hurst, S., Helmich, C., Headley, D., Martin, M., \& Boyle, D. A. (2008). Acinetobacter baumannii: an emergingmultidrug-resistan pathogen in critical care. Crit Care Nurse, 28(1), 15-25. https://doi.org/10.4037/ccn2008.28.1.15

Moriel, D. G., Beatson, S. A., Wurpel, D. J., Lipman, J., Nimmo, G. R., Paterson, D. L., \& Schembri, M. A. (2013). Identification of Novel Vaccine Candidates against Multidrug-Resistant Acinetobacter baumannii. PLoS One, 8(10), e77631. https://doi.org/10.1371/journal.pone.007763

Pachon, J., \& McConnell, M. J. (2014). Considerations for the development of a prophylactic vaccine for Acinetobacter baumannii. Vaccine, 32(22), 2534-2536. https://doi.org/10.1016/j.vaccine.2013.10.064

Pavlica, R., \& Tomanovic, B. (1989). [Acinetobacter calcoaceticus as a cause of infection in wounds and burns]. Srp Arh Celok Lek, 117(5-6), 319-324.

Peleg, A., Seifert, H., \& Paterson, D. L. (2008). Acinetobacter baumannii: emergence of a successful pathogen. Clin Microbiol Rev, 21(3), https://doi.org/10.1128/CMR.00058-07

Perez, F., Hujer, A. M., Hujer, K. M., Decker, B. K., Rather, P. N., \& Bonomo, R. A. (2007). Global Challenge of Multidrug-Resistant Acinetobacter baumannii $\begin{array}{llll}\text { Antimicrob Agents } \quad \text { Chemother, } & \text { 31(10), }\end{array}$ https://doi.org/10.1128/AAC.01464-06

Qureshi, Z. A., Hittle, L. E., O'Hara, J. A., Rivera, J. I., Syed, A., Shields, R. K. Pasculle, A. W.,Ernst, R. K. Doi, Y. (2015). Colistin-resistant Acinetobacter baumannii: beyond carbapenem resistance. Clin Infect Dis, 60(9), 1295-1303. https://doi.org/10.1093/cid/civ048

Rollauer, S. E., Sooreshjani, M. A., Noinaj, N., \& Buchanan, S. K. (2015). Outer membrane protein biogenesis in Gram-negative bacteria. Philos Trans $R$ Soc Lond B Biol Sci, 370(1679). https://doi.org/10.1098/rstb.2015.0023

Russo, T. A., Luke, N. R., Beanan, J. M., Olson, R., Sauberan, S. L., MacDonald, U., Schultz, L. W., Umland, T. C.,Campagnari, A. A. (2010). The K1 capsular polysaccharide of Acinetobacter baumannii strain 307-0294 is a major virulence factor. Infect Immun, 78(9), 3993-4000. https://doi.org/10.1128/IAI.00366-10

Wang-Lin, S. X., Olson, R., Beanan, J. M., MacDonald, U., Balthasar, J. P., \& Russo, T. A. (2017). The Capsular Polysaccharide of Acinetobacter baumannii Is an Obstacle for Therapeutic Passive Immunization Strategies. Infect Immun 85(12), e00591-00517. https://doi.org/10.1128/IAI.00591-17 